Innovations

in Global Health Professions

Education

\title{
The power of an iterative approach to clinical competence assessment
}

\section{Authors}

Kimberly Gifford ${ }^{1 *}$; Jalen Benson'; Julie Kim

\section{Abstract}

Many residency programs struggle with effective and efficient methods for their program to synthesize and analyze data to create robust milestones-based assessment of residents.

Residents and faculty in the Pediatric Residency at Dartmouth-Hitchcock Medical Center collaborated to design an innovative iterative process for resident assessment using rotation-based Milestones reports, faculty sub-committees, and discussion with the resident. Time spent and frequency of Milestones determinations made at each phase of assessment process were tabulated and feedback summarized from faculty, residents, and administrators. Our new process integrated milestones determinations into our existing committee review structure without any additional time added to the process. Faculty perceived that the system was efficient and provided more insight about each resident. The program director used the sub-committee summaries for semi-annual reviews and letters of reference. Residents appreciated the fairness of all residents being reviewed by the same faculty. Milestones determinations were made by: evaluations alone (69\%), Clinical Competency Committee (CCC) sub-committee (18\%), full CCC (7\%), and additional data or PD decision (6\%). The full CCC was needed more frequently for professionalism and systems-based practice Milestones determinations. Iterative assessment systems have the potential to save valuable faculty time without compromising the quality of assessments.

\section{Keywords}

assessment; milestones; graduate medical education; residency; clinical competence

\section{Background and purpose}

In 2012, the Accreditation Council for Graduate Medical Education (ACGME) established a new evaluation paradigm requiring residency programs to assess resident's achievement of educational milestones through Clinical Competency Committees (CCC). As programs have shared their experiences, some best practices have begun to emerge to improve assessment quality'; however, many programs still struggle with the feasibility of these assessment practices and there are few
'Geisel School of Medicine at Dartmouth, Hanover, NH, United States of America

*Email: kimberly.a.gifford@hitchcock.org

\section{Cite this article as:}

Gifford K, Benson J, Kim J. The power of an iterative approach to clinical competence assessment. Innovations in Global Health Professions Education. 2018:2. http://dx.doi.org/10.20421/ ighpe2018.02

This is an open access article distributed under the terms of the Creative Commons Attribution license CC BY 4.0, which permits unrestricted use, distribution and reproduction in any medium, provided the original work is properly cited. 
recommendations for how to improve efficiency of the assessment process. Some programs have competency champions or assigned CCC members to review each resident ${ }^{2-4}$; however, residents question the fairness of these assignments. ${ }^{4}$ Other programs group ${ }^{5}$ or map milestones to Entrustable Professional Activities (EPA). ${ }^{6}$

Prior to these new expectations, our longstanding university-affiliated program of 21 categorical Pediatric residents (7residents/year) used Likertscale evaluations. Evaluations were reviewed by the Program Director (PD) and presented to a group of core faculty members, who discussed their experiences with residents. Our evaluations lacked behavioral anchors and data was difficult to synthesize across settings and through our evaluations management system. In the absence of more concrete data, discussions occasionally devolved into subjective generalizations.

Furthermore, the process depended heavily on the PD's perspective and effort (lhour/resident pre-CCC and lhour/resident post-CCC). Thus, we aimed to restructure our assessment system to meet the requirements for CCC Milestone assessment by maximizing our faculty expertise to create more robust assessments in a fair, efficient, and feasible way.

\section{Setting, conditions and format}

Our Program Evaluation Committee (PEC), with both resident and faculty representatives, developed guiding principles for creation of our CCC through group discussion of important themes for each of the stakeholders:

A. All residents should be reviewed by the same faculty to minimize the impact of faculty bias;

B. Faculty have variable interests and abilities in assessing different competencies;

C. Faculty could not commit to significantly more time for assessment;

D. We could not build or buy a new evaluation system;

E. Assessments from direct observation and 360 evaluations may be better interpreted by rotation directors, who better understand the context and evaluators, than by the full CCC.

After rejecting the approaches taken by most other programs, the PEC determined that an iterative system would best accomplish these goals. The iterative steps in the assessment system are as follows:

1. To address principles C-E above, each rotation director completed a Milestones report based on existing assessment tools in their setting, such as direct observations and interdisciplinary feedback. Rotationbased Milestones reports contained 8-12 of the 21 sub-competencies reported to the ACGME using Pediatric Milestones language adapted to their setting by the rotation director, 1-3 EPAs with anchors for level of entrustment ${ }^{7}$ and free text comments for strengths and strategies for improvement.

\section{Program administrators exported} Milestones reports, and compiled data.

3. To address principles A-B, the CCC was divided into 3 subcommittees. Each subcommittee reviewed all residents for a subset of competencies (see Table 1): (1) patient care and medical knowledge (PC/MK); (2) interpersonal skills and communication, systems-based practice and some professionalism (ISC/SBP); (3) practice based learning and improvement and professionalism (PBLI/PROF). Faculty were selected for each subcommittee based on expressed interest and expertise demonstrated by engagement in committees and continuing education in the domain. Competencies were placed in each subcommittee group based on the competency domain in which they were defined for the Pediatric Milestones. The professionalism domain that focuses on professional behaviors were related to communication, so were grouped with ICS/SBP. The professional development competencies were grouped with PBLI. Each subcommittee reviewed the data specific to their competencies and developed a summary. 


\begin{tabular}{|c|l|l|l|l|l|l|l|l|}
\hline & Subcommittee & \multicolumn{1}{|c|}{ Competency } & \multicolumn{5}{|c|}{ Resident } \\
\hline \multirow{2}{*}{$\begin{array}{c}\text { Competency } \\
\text {-based groups } \\
\text { (Dartmouth ap- } \\
\text { proach) }\end{array}$} & & & A & B & C & D & E & F \\
\hline & Group 1 & PC/MK & & & & & & \\
\hline & Group 2 & ISC/SBP & & & & & & \\
\hline & Group 3 & PBLI/PROF & & & & & & \\
\hline & & & & & & & & \\
\hline & Group 1 & PC/MK & & & & & & \\
\hline & & ISC/SBP & & & & & & \\
\hline
\end{tabular}

Table 1. CHaD CCC approach with competency-based subcommittees (top) in which every resident is reviewed by all subcommittees for a subset of competencies in contrast to the resident-assigned approach used by some other programs (bottom) in which faculty members

(or groups) review all competencies for a subset of residents.

4. The full $\mathrm{CCC}$, facilitated by the Program Director, reviewed the subcommittee summaries, discussed areas of discrepancy, and recommended strategies. All 31 core faculty were invited to the CCC meeting with 10-15 attending regularly. Each subcommittee briefly highlighted strengths, areas for improvement, areas of discrepancy in evaluations, missing data, and questions for the full CCC. Guidelines for discussion were developed:

- Evaluate each learner individually and avoid comparison to other learners

- Evaluate performance, not personality

- Focus on concrete examples, not opinions

- Outline expectations for the learner to enhance future learning

- Identify supports to help the learner reach their goals.

5. The Program Director gathered additional data when needed and compared the CCC
Milestones with the resident's Milestonesbased self-assessment. During the resident's semi-annual review, the Program Director discussed areas of discrepancy between the CCC and self-assessments, relative strengths and weakness, resident's goals progression and plans for next steps. Milestones reported to the ACGME were modified from the CCC recommendations in 2-3 instances per reporting period ( $<1 \%$ of Milestones reported across all residents) based on discussion with the resident and better investigating the resident's internal thought processes that were not clear to the CCC.

\section{Analytical methods}

We implemented our new system in the fall of 2012. After two semi-annual cycles (summer 2013), informal feedback was gathered to improve the CCC process. Residents and faculty were asked to share general perceptions about the CCC process, strengths, challenges, and suggestions. The PD (KG) facilitated a feedback meeting with the CCC and met with the Program Coordinator and sub-group chairs (one of which was JK). JK and KG summarized feedback from the CCC and 
then shared the summary with the CCC to ensure accuracy. The chief resident facilitated a feedback meeting with residents in the absence of program leadership and faculty. To examine feasibility, we asked each CCC subgroup to report the time spent in each phase of the assessment process and calculated "person-minutes" by multiplying the number of people participating in the phase by time spent.

To examine the role of each phase in the assessment process, for each competency we determined the proportion of residents for whom each of the following phases was the determining factor in final milestones assignments during the 2014-2015 academic year (cycles 5-6).

- Rotation Milestones report decisions were defined by two or more rotation Milestones reports that were within 0.5 milestone level.

- CCC sub-committee decisions included rotation-based comments and discussion between CCC members. The PBLI subcommittee included examination of the resident's portfolios.

- Full CCC decisions involved group discussion of areas of discrepancy or insufficient data.

- Program Director final assessment included additional data collected beyond the full CCC meeting and discussion with residents.

\section{Situation analysis and outcomes}

\section{CCC group process}

Our iterative clinical competency assessment system has many advantages that have been highlighted as recommendations for CCCs by a review of the literature on group decision making. ${ }^{8}$ We convened a heterogeneous group of faculty selected for their complimentary skill sets and interests. However, CCC time was not protected. Through discussion we developed a shared understanding of Milestones, common language to discuss them, and guidelines for structured discussion. The CCC thought that rotation directors were better able to synthesize observations and assessments from their clinical setting compared to CCC members who may not know the context. Additionally, our structure improved information sharing by focusing discussion on data and observations to support arguments. Our format also mitigated bias by allowing the program director to function as a facilitator who promoted sharing of dissenting opinions and suggestions made by the CCC subcommittees. The formation of CCC subcommittees led to improved sharing of workload and better preparation. Additionally, our unique structure overcame the potential bias of different faculty members reviewing different groups of residents without the substantial faculty development needed by other programs to achieve agreement across numerous reviewers.

\section{Faculty perceptions}

CCC members appreciated being able to focus on competencies that were of most interest to them. Full CCC meetings were viewed as more efficient when focusing on strengths, areas of improvement, discrepancies and questions identified by the subcommittees. Questions raised by one subcommittee were frequently answered by another subcommittee, which led to a richer discussion. Dissenting opinions often provided insights not otherwise apparent. Rotation directors also appreciated learning how to help all residents in future rotations (not just those needing remediation). The program director used the subcommittee summaries to create qualitative summaries and letters of recommendation.

\section{Resident perceptions}

Residents were pleased that our system addressed their biggest concern of fairness, a concern shared by residents in other programs ${ }^{4}$, by having all residents reviewed by the same faculty. Residents initially thought that integration of Milestones into semi-annual review meetings emphasized past performance over future career planning. However, after residents became familiar with the Milestones framework, meetings were able to refocus on their progress, goals and career planning.

\section{Feasability}

The CCC process required 220 person-minutes/ resident (Table 2), which was unchanged from the 
overall time required prior to using Milestones. Meeting duration was unchanged, but the distribution of time focused more on identifying strategies to help struggling residents. Prior to using Milestones, the PD spent 1 hour pre-CCC and lhour post-CCC per resident as compared to the iterative system which required $15 \mathrm{~min}$ pre-CCC for each member and $45 \mathrm{~min} /$ resident post-CCC for the PD to create the CCC summary, meet with the resident, and share assessments with the resident's mentorship team. The total time commitment for each CCC member was 17.5 hours/year. Our new process integrated milestones determinations into our existing committee review structure while slightly reducing the total time required. The efficiency of our process, 220 person-minutes per resident, was on the lower end of 3-6 hours per resident reported across programs $^{9}$ and similar to other programs who did more pre-meeting data synthesis. ${ }^{2,4}$ While a strength of our approach is broad faculty engagement, it also shifted some of the time needed to review the data from the PD to the CCC. Other programs across disciplines have also reported similar time challenges for faculty. 2-4,9 Our CCC faculty found the added time to be manageable and appreciated that time being focused on their areas of interest.

\section{Role of each phase of the assessment process}

Figure 1 shows the percent of Milestones determinations made at each phase: evaluations (69\%), CCC sub-committee (18\%), full CCC (7\%), and additional data or PD decision (6\%). Nearly $90 \%$ of the determinations were based on rotation-specific milestone reports for PBLI1 (self-assessment), ICS1 (patient communication) and ICS2 (empathy). We

\begin{tabular}{|l|l|l|c|c|}
\hline \multicolumn{1}{|c|}{ Timeline } & Responsible party & \multicolumn{1}{|c|}{ Description of phase } & $\begin{array}{c}\text { Mean time spent } \\
\text { per resident }\end{array}$ & $\begin{array}{c}\text { Person-minutes* } \\
\text { per resident }\end{array}$ \\
\hline On-going & Rotation Directors & $\begin{array}{l}\text { Submit rotation-specific mile- } \\
\text { stones reports to the program } \\
\text { based on setting-specific as- } \\
\text { sessments }\end{array}$ & Variable & Variable \\
\hline $\begin{array}{l}2 \text { weeks prior } \\
\text { to CCC }\end{array}$ & Program Coordinator & $\begin{array}{l}\text { Compile rotation-specific mile- } \\
\text { stone reports and comments for } \\
\text { the CCC members }\end{array}$ & 10 min & 10 min \\
\hline $\begin{array}{l}\text { By } 2 \text { days } \\
\text { prior to full } \\
\text { CCC meeting }\end{array}$ & CCC Sub-committee & $\begin{array}{l}\text { Review data, assign proposed } \\
\text { milestone levels and draft sum- } \\
\text { mative evaulation for assigned } \\
\text { sub-competencies }\end{array}$ & 15 min & 90 min \\
\hline $\begin{array}{l}\text { CCC meet- } \\
\text { ing for core } \\
\text { faculty }\end{array}$ & $\begin{array}{l}\text { Sub-committee } \\
\text { chairssummarize res- } \\
\text { ident assessments; } \\
\text { Program director } \\
\text { Facilitates }\end{array}$ & $\begin{array}{l}\text { Present sub-committee summa- } \\
\text { ries and questions followed by } \\
\text { full CCC discussion }\end{array}$ & $\begin{array}{l}10 \text { min } \\
\text { (range 5-15 min) }\end{array}$ & 120 min \\
\hline $\begin{array}{l}\text { After CCC } \\
\text { meeting }\end{array}$ & Program Director & $\begin{array}{l}\text { Finalize summative evaluations, } \\
\text { conduct seimannual review with } \\
\text { resident, follow-up with resi- } \\
\text { dent's mentorship team }\end{array}$ & 45 min & 45 min \\
\hline $\begin{array}{l}\text { After semi- } \\
\text { annual } \\
\text { review }\end{array}$ & $\begin{array}{l}\text { Program Coordinator } \\
\text { and Program Director }\end{array}$ & $\begin{array}{l}\text { Mllestones are submitted to } \\
\text { ACGME }\end{array}$ & 5 min & 5 min \\
\hline
\end{tabular}

Table 2. Timeline and mean time spent during each phase of the CCC process 
attributed the efficiency of our process to the iterative structure that enabled us to forgo discussion about competencies that showed good agreement across settings, such as communication. We were not surprised by this finding because communication competencies often develop early and are more stable across settings. ${ }^{10} \mathrm{CCC}$ subgroup discussion was more important for patient care, medical knowledge, and trustworthiness due to variability in Milestones across settings. The variability in these competencies across settings demonstrates differences in context. The subcommittees determined milestone levels for these competencies using rotation-based comments and their own experiences with the learners. These subcommittee decisions were usually supported by the full CCC and needed little discussion, again

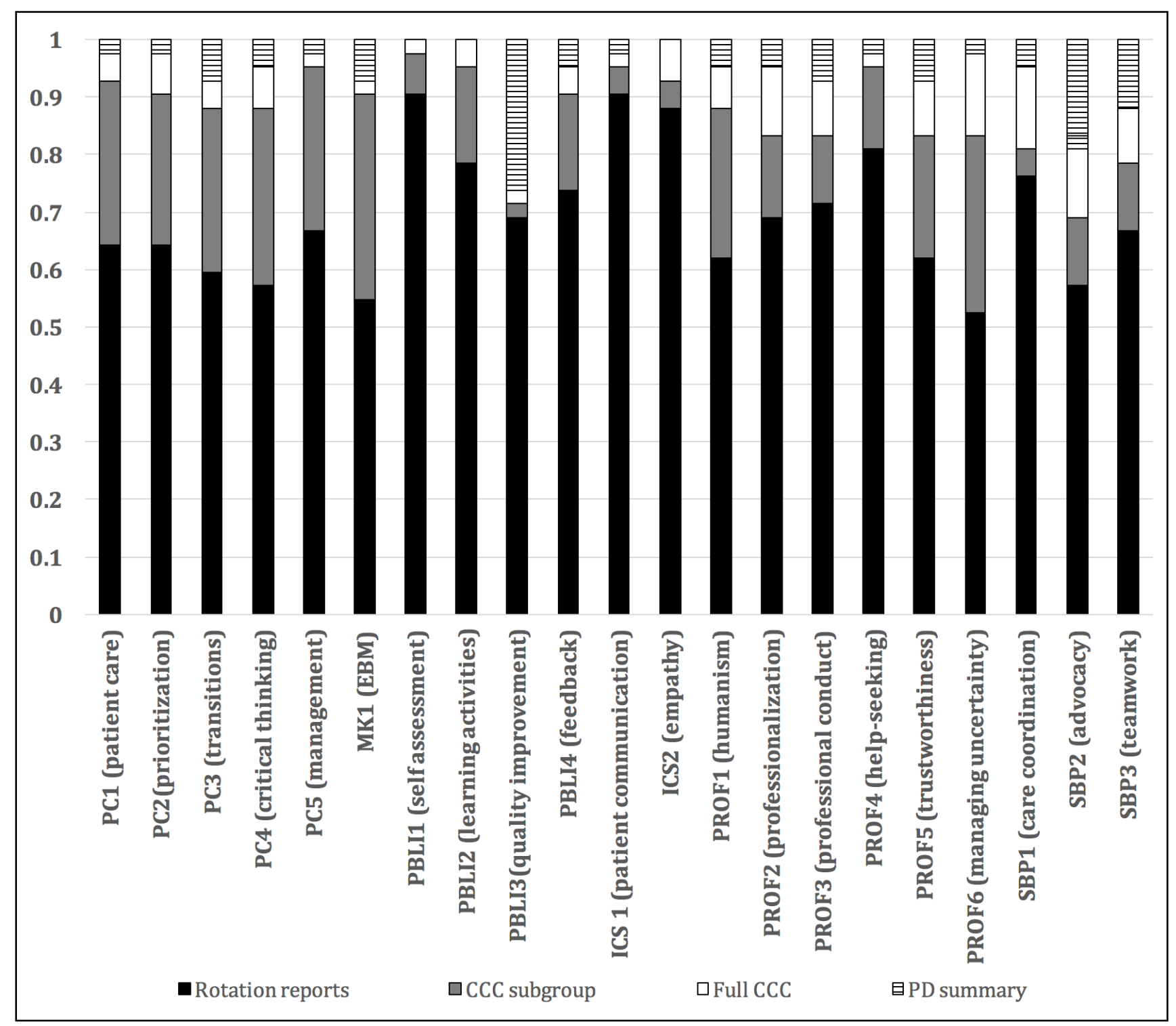

Figure 1. Decisions based on rotation-specific milestone reports (black) were defined by two or more rotation evaluations that were within 0.5 milestone level. Decisions made by CCC sub-committee (gray) also included rotation-based comments and discussion between CCC members. The PBLI sub-committee also include examination of the resident's portfolios. Decisions made by full CCC (white) involved large group discussion of areas of discrepancy or insufficient data. Program Director final assessment (spotted) included any additional data collected beyond the full CCC meeting and discussion with the residents about their self-assessments. 
improving efficiency. Full CCC discussion was most important for professionalism and systems-based practice. There was greater uncertainty at the subcommittee level when evaluating professionalism and systems-based practice, possibly due to the complexity of these competencies, which necessitated discussion in the full CCC. Finally, PD discussion with the resident or project mentors was most necessary to determine Milestones level for PBLI3 (Quality Improvement). Overall, discussion at every level (rotation, subgroup, full CCC, and resident) was a vital component to determining milestone levels.

\section{Summary}

Overall, our iterative clinical competency assessment system has optimized the use of faculty time. as we implemented milestones-based assessments. Faculty and residents agree that the process is fair and produces a more robust assessment with concrete improvement suggestions. The keys to success were including all stakeholders in the development of our system, broad engagement of faculty in an iterative manner, and the use of standardized discussion as a tool for interpreting evaluations.

We continue to use feedback from residents and faculty to hone our processes and data from the roles of each phase of the assessment process to refine our rotation milestone reports. Our process could be replicated at another program in any discipline with minimal need for new faculty development by restructuring the existing CCC to review sets of competencies for all residents. The analysis we used to examine the role of various phases in the assessment process could be applied to other frameworks for organizing assessment systems, such as EPAs. Over time this data, regarding which competencies require more discussion time in the CCC, could be used to further streamline the assessment process. Our approach may be more challenging at a large program; however, in that setting, programs may choose to narrow the scope of each subcommittee to a smaller group of subcompetencies or groups of residents. The power of an iterative approach to save time may also be magnified in a larger program. Ultimately, iterative assessment systems have the potential to save valuable faculty time without compromising the quality of assessments.
Acknowledgements: The authors thank Cameron Cudhea for data management, CCC subgroup chairs (Catherine Shubkin, MD and Adam Weinstein, MD) and other active CCC members who participated in the design of our system (Todd Poret, MD, Sara Chaffee, MD, Samantha House, DO, MPH). The authors acknowledge Patricia Hicks, MD, MHPE for suggesting the concept of examining milestone decisions at each phase in the assessment process.

\section{Conflicts of interest: None.}

Funding sources: None.

\section{References}

1. Andolsek K, Padmore J, Hauer KE, Edgar L, Holmboe E. Clinical competency committees: a guidebook for programs [Internet] 2nd ed. Chicago, IL: Accreditation Council for Graduate Medical Education; 2015 [updated 2017 Sep 23; cited 2018 Jul 4]. 73 p. Available from: https://www.acgme.org/Portals/0/ ACGMEClinicalCompetencyCommitteeGuidebook. pdf.

2. Nabors C, Forman L, Peterson SJ, Gennarelli $M$, Aronow WS, DeLorenzo L, et al. Milestones: a rapid assessment method for the Clinical Competency Committee. Arch Med Sci [Internet]. 2017 Feb 1 [cited 2018 Jul 4]; 13(1):201209. Available from: https://doi.org/10.5114/ aoms.2016.64045

3. Ketteler ER, Auyang ED, Beard KE, McBride EL, McKee R, Russell JC, et al. Competency champions in the clinical competency committee: a successful strategy to implement milestone evaluations and competency coaching. J Surg Educ. 2014 JanFeb;71(1):36-8. doi: 10.1016/j.jsurg.2013.09.012

4. Donato AA, Alweis R, Wenderoth S. Design of a clinical competency committee to maximize formative feedback. J Community Hosp Intern Med Perspect [Internet]. 2016 Dec 15 [cited 2018 Jul 4]; 6(6):33533 [6 p.]. Available from: https://doi.org/10.3402/jchimp.v6.33533

5. Schumacher DJ, Sectish TC, Vinci RJ. Optimizing clinical competency committee 
work through taking advantage of overlap across milestones. Acad Pediatr. 2014 SepOct;14(5):436-8. doi: 10.1016/j.acap.2014.06.003

6. Choe $\mathrm{H}$, Knight $\mathrm{CL}$, Stiling $\mathrm{R}$, Corning $\mathrm{K}$, Lock K, Steinberg KP. Shortening the miles to the milestones: connecting EPA-based evaluations to ACGME milestone reports for internal medicine residency programs. Acad Med. 2016 Jul;91(7):943-50. doi: 10.1097/ acm.0000000000001161

7. ten Cate 0 . Nuts and bolts of entrustable professional activities. J Grad Med Educ [Internet]. 2013 Mar [cited 2018 Jul 4]; 5(1):1578. Available from: https://doi.org/10.4300/ jgme-d-12-00380.1

8. Hauer KE, Cate OT, Boscardin CK, lobst W, Holmboe ES, Chesluk B, et al. Ensuring resident competence: a narrative review of the literature on group decision making to inform the work of clinical competency committees. J Grad Med Educ [Internet]. 2016 [cited $2018 \mathrm{Jul} 4$ ]; 8(2):156-64. Available from: https://doi.org/10.4300/jgme-d-15-00144.1

9. Hong R. Observations: we need to stop drowning-a proposal for change in the evaluation process and the role of the clinical competency committee. J Grad Med Educ [Internet]. 2015 [cited 2018 Jul 4]; 7(3):4967. Available from: https://doi.org/10.4300/ igme-d-15-00131.1

10. Warm EJ, Mathis BR, Held JD, Pai S, Tolentino J, Ashbrook L, et al. Entrustment and mapping of observable practice activities for resident assessment. J Gen Intern Med [Internet]. 2014 [cited $2018 \mathrm{Jul} 4$ ]; 29(8):1177-82. Available from: https://doi.org/10.1007/s11606-014-2801$\underline{5}$ 